\title{
Temporal Variation in Shear Wave Anisotropy Detected with ACROSS
}

\author{
Ryoya Ikuta and Koshun Yamaoka \\ Graduate School of Environmental Studies, Nagoya University, Nagoya, 464-8602, Japan.
}

\begin{abstract}
We are now developing a seismic exploring system named ACROSS aiming at detection of temporal variation in elastic properties of the crust. We made an experiment lasting for 15 months, from January 2000 to April 2001 at a site near the Nojima fault, which ruptured during the 1995 Kobe earthquake (Mw7.2). Elastic waves generated by surface-deployed ACROSS sources were received with seismometers deployed in the bottom of $800 \mathrm{~m}$ - and $1700 \mathrm{~m}$-deep boreholes near the sources. During the experiment, sudden delays in travel times for $\mathrm{S}$ wave were observed at the time when the 2000 WesternTottori earthquake (Mw6.6) and the 2001 Geiyo earthquake (Mw6.7) occurred. The traveltimes of the $\mathrm{S}$ waves abruptly delayed and gradually recovered associated with each earthquake with little change in that of $P$ waves. The delay was about $0.4 \%$ and $0.1 \%$ of absolute travel time for the Western-Tottori earthquake and Geiyo earthquake, respectively. The delays were polarized in a direction perpendicular to the Nojima fault for both cases. This suggests that the density of the cracks parallel to the fault increased associated with the earthquakes. These cracks can be regarded as being opened by an increase of pore-pressure. An additional experiment determining the static structure revealed that the preferred orientation of the cracks had existed and be enhanced with the strong shaking of the earthquakes in middle distance.
\end{abstract}

\section{Introduction}

We are developing an artificial vibration source system especially for monitoring the temporal variation of the velocity in $\mathrm{P}$ and $\mathrm{S}$ waves [Yamaoka et al, 2001]. The primary feature of the system is to generate sinusoidal waves that are accurately controlled with reference to GPS clock. This system enables us to make a continuous monitoring of the seismic wave propagation without destroying the surrounding ground. We have made a 15 months continuous experiment using this system from Jan. 2000 to Apr. 2001 at a site in Awaji Island, Japan. Ikuta et al. [2002] reported the results of this experiment and showed the potential ability of ACROSS. They have also estimated the uncertainty of $\mathrm{S}$ wave travel time no more than $0.1 \mathrm{~ms}$ in about $1 \mathrm{~km}$ between source and receivers. During the experiment, sudden decreases of $\mathrm{S}$ waves velocity were observed at the time when the 2000 Western-Tottori earthquake (WT; Mw6.6) and the 2001 Geiyo earthquake (GY; Mw6.7) occurred. In this paper, we focus on the changes in the anisotropy at the time of the WT and the GY earthquake by using $\mathrm{S}$ wave polarizations.

\section{Travel time monitoring with ACROSS}

A long term monitoring of the seismic velocity using ACROSS was carried out from January, 2000 to April, 2001 near the Nojima fault, which ruptured at the 1995 Kobe earthquake (Figure 1). In the experiment, ACROSS vibrators worked almost continuously 
without troubles except for planned or unexpected power shutdowns. As the details of this experiment have already been published by Ikuta et al.,2002, we describe briefly on the experiment at the Awaji site.

\subsection{Site}

Two ACROSS vibrators, one is designed to produce sinusoidal wave up to $35 \mathrm{~Hz}$ and the other up to $25 \mathrm{~Hz}$ with a maximum force of $2.0 \times 10^{5} \mathrm{~N}$, are deployed at the ground surface (Figure 2). Hereafter they are called HF (High Frequency) and LF (Low Frequency) unit, respectively. The ACROSS sources are designed to generate a sinusoidal force by rotating an eccentric mass around a vertical axis. The rotation generates a single force in all direction in the horizontal plane.
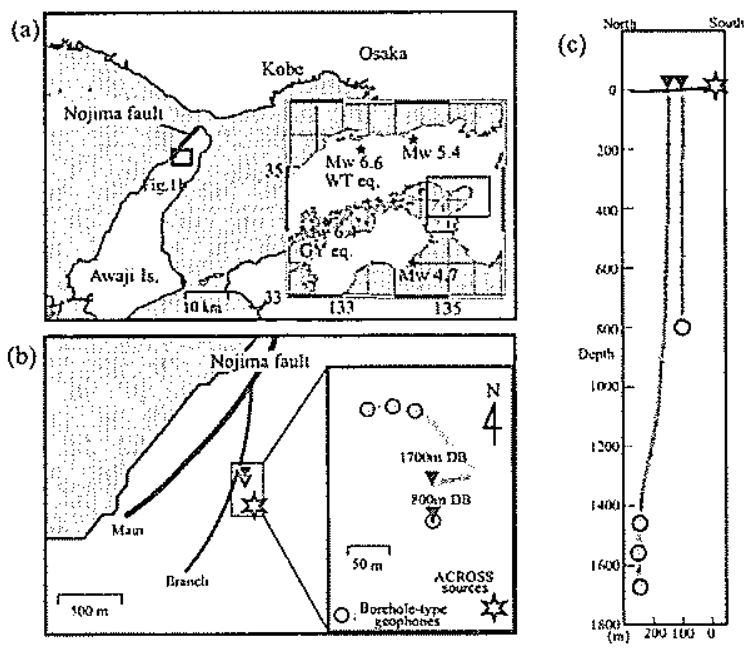

Fig. 1. Location of the ACROSS experiment site near the Nojima fault.

(a) Location of the ACROSS site. ACROSS site is marked by solid star. Heavy line indicates Nojima fault. (b) Location of the ACROSS vibrators (open star) and seismometers. Solid triangles denote the $1700 \mathrm{~m}$ - and $800 \mathrm{~m}$-deep boreholes. The enlarged map at the bottom right shows the observation setting. Heavy gray lines are traces of $1700 \mathrm{~m}$ - and $800 \mathrm{~m}$ - boreholes. Open circles denote borehole-type seismometers. (c) North-South vertical cross section showing the geometry of the $800 \mathrm{~m}$ - and $1700 \mathrm{~m}$-deep boreholes.
Four three-component velocity sensors with a natural frequency of $1.0 \mathrm{~Hz}$ were deployed around the sources to record the actual vibration. The records are used afterwards for correction. Three of them were placed on the foundation and one was deployed at the bottom of the $10 \mathrm{~m}$-deep borehole.

Two deep boreholes whose depths are $800 \mathrm{~m}$ and $1700 \mathrm{~m}$ are drilled near the ACROSS vibrators. They are $120 \mathrm{~m}$ and $180 \mathrm{~m}$ away from the source, respectively. A three-component velocity sensor, accelerometer, and a three-component strain meter were installed at the bottom of the $800 \mathrm{~m}$ borehole. A water pressure gauge was also installed in the $800 \mathrm{~m}$-borehole. The gauge measures pore pressure at the bottom of the borehole. In the $1700 \mathrm{~m}$-borehole, a three-component velocity sensor was installed at the bottom. Hereafter we shall call the seismometers installed at the bottoms of the two boreholes as $800 \mathrm{~m}$ - and $1700 \mathrm{~m}$-borehole sensor, respectively. In the experiment we intended to detect the temporal variation of the signal recorded with these sensors.

\subsection{Operation Parameters for ACROSS system}

The HF and LF sources were operated simultaneously with frequency modulation to cover as wide frequency range as possible. 


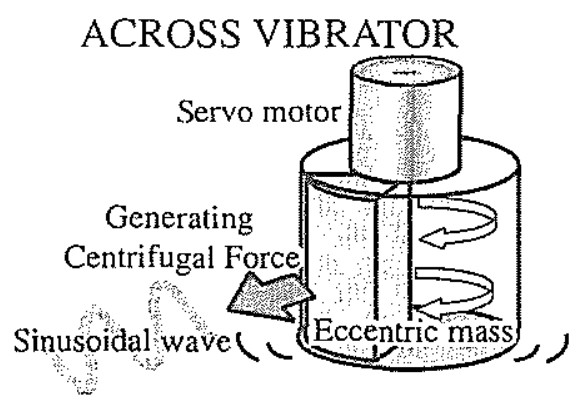

Fig. 2. Schematic illustration of ACROSS vibrator.

ACROSS vibrator generates sinusoidal waves by rotating an eccentric mass around a vertical axis.
The $\mathrm{HF}$ and $\mathrm{LF}$ units were operated with the same modulation amplitude of $2.5 \mathrm{~Hz}$ and modulation period of 5 second, but with the different rotational frequency centered at $13 \mathrm{~Hz}$ and $19.1 \mathrm{~Hz}$, respectively. We can identify the phase arriving at the sensors within 5 seconds after excitation by the source because the sources repeated same frequency modulation with the interval of 5 seconds. Data were sampled at $100 \mathrm{~Hz}$ with the resolution of 24bits and stacked with the interval of 100 seconds. The data were saved once per hour so that each dataset consists of 36 stacks. Before stacking, each 100 second-long data was normalized by its maximum amplitudes to suppress the effect of incidental large external noise such as natural earthquakes.

\section{Changes in $\mathrm{S}$ wave travel times associated with earthquakes in middle distance}

We estimated temporal variation in the travel time of ACROSS signal observed during the experiment using cross spectral density (CSD) method.

\subsection{Analysis for temporal variation in travel time of ACROSS signal}

In the analysis we calculated temporal variation in the travel time for $\mathrm{P}$ and $\mathrm{S}$ waves for the data recorded at $800 \mathrm{~m}$ - and $1700 \mathrm{~m}$-borehole sensors for two period including the time of the WT and the GY earthquakes. We adopted the method described in Ikuta et al. [2002] to estimate the temporal travel time variation.

Fourier amplitude spectra of the observed data are shown in Figure 4. Spectral peaks in it corresponds to the signal. Extracted signal was divided by the force generated by the source in frequency domain. The result is regarded as a transfer function (or band-limited impulsc response) between the source and the receivers. Applying inverse Fourier transformation we can obtain the signal in time domain (Figure 4). To detect small temporal variations in the wave traces, we calculated cross-spectral densities (CSD) among the traces on the sections including $\mathrm{P}$ or $\mathrm{S}$. We extracted $\mathrm{P}$ and $\mathrm{S}$ phases by applying Hanning window on each trace as shown in Figure 4. CSD were calculated with reference to the trace at 12:00 of September 13,2000 for the period including the WT earthquake and 12:00 of January 13, 2001 for that including the GY, which gives the relative variation of travel time:

$$
\Delta T=\left\langle\theta_{i} / \omega_{i}\right\rangle
$$

where $\theta_{i}$ is the relative phase variation of $i$-th frequency component obtained by CSD calculation and $\omega_{i}$ is its angular frequency. Relative travel time is obtained by averaging them 
over all the available spectral components from 10 to $22 \mathrm{~Hz}$. In averaging, each delay is weighed by the square root of the amplitude.

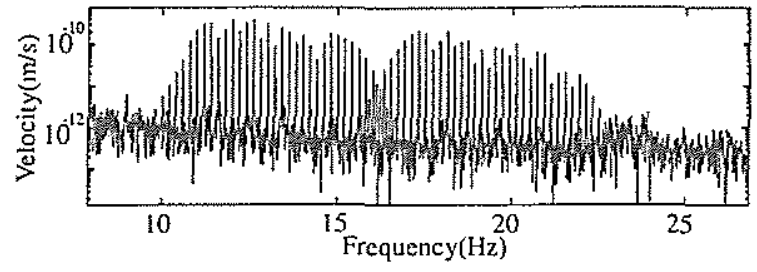

Fig. 3. An example of Fourier amplitude spectra Fourier amplitude spectra for the vertical component of the $800 \mathrm{~m}$-borehole sensor after one hour stack. Two robes ranging from 10 to $17 \mathrm{~Hz}$ and from 15 to $23 \mathrm{~Hz}$ correspond to the LF and HF units, respectively. The spectral peaks coming from each unit have constant interval of $0.2 \mathrm{~Hz}$ as the frequency moduration period is 5 seconds. Note the spectral peaks for two sources do not overlapped because the central frequency of the $\mathrm{HF}$ unit is shifted by $0.1 \mathrm{~Hz}$ away from the integer multiples of $0.2 \mathrm{H}$, which is the interval of the spectral peaks.

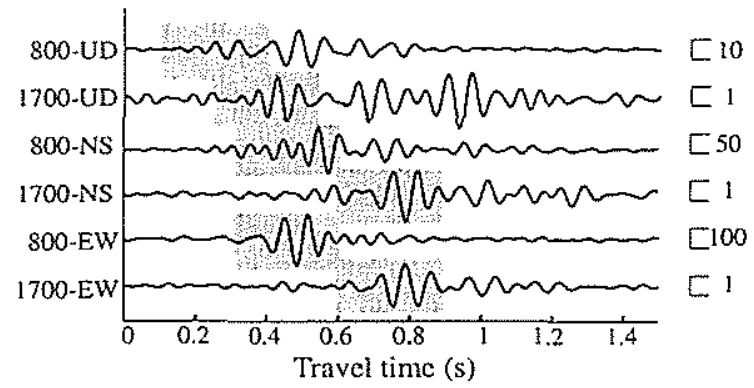

Fig. 4. Transfer functions

Transfer functions between the ACROSS sources and borehole sensors. Gray patches show the part to which the Hanning windows are applied to extract $\mathrm{P}$ or $\mathrm{S}$ phases.

Figure 5-a and 6-a show the results of the travel time analysis applied on $\mathrm{P}$ and $\mathrm{S}$ phases and precipitation. The travel time of $S$ waves delayed with rain falls as well as at the time of the WT and the GY earthquakes. Gradual delays and subsequent recoveries are seen following rainfalls. The travel time delays associating with rainfall were already reported by Yamaoka et al.[2001] and Ikuta et al.[2002]. This phenomenon is probably not caused by the variation of the seismic wave velocity but by the variation of the elastic nature of the soil surrounding the source, which affects the motion of the source. The rainfall shortly after the GY earthquake may affect on the record which includes presumable faint travel time variation at the time of the earthquake. To correct the effect, we adopted the method they applied to the records. The result is shown in Figure 6-a'. Hereafter we consider it to the travel time variation for the period including the GY.

\subsection{Changes in travel time}

The travel times of $\mathrm{S}$ wave between the sources and the $800 \mathrm{~m}$-borehole sensor suddenly delayed (the velocities decreased) by $0.4 \%$ at the time of the WT and $0.1 \%$ at the GY earthquake, though the changes were hardly observed in the $\mathrm{P}$ phases for both the earthquakes (see Figure 5-a, 6-a'). O'connell and Budiansky [1974] made several important statements on the relation between cracked solid and seismic waves. They showed that the seismic velocities decrease with increasing crack density. They also showed that the $V_{P} / V_{S}$ decreases for dry cracks and increases for fluid saturated cracks with increasing crack density. According to their theoretical result, $\mathrm{S}$ wave velocity decreases at least 2.5 times larger than $\mathrm{P}$ wave velocity does as the crack density increase for the case in which all the cracks are saturated with water. This may account for our analytical result. The sudden delays of travel time in $\mathrm{S}$ wave suggests that they were caused by a sudden increase of pore pressure which opened 
the cracks. For both cases, the travel time recovered following exponentially-decay function. It also supports the model. The velocity changes were associated with sudden increase and diffusion of fluid pressure.

The amount of the delay in the $\mathrm{S}$ wave travel time at the $800 \mathrm{~m}$-borehole sensor at the time of the WT was equivalent to that at the $1700 \mathrm{~m}$-borehole one (see Figure 5 -a), though the delay at the $1700 \mathrm{~m}$ one did not have enough resolution at the time of GY. The cause of the change at least at the time of the WT was restricted in the portion shallower than $800 \mathrm{~m}$.
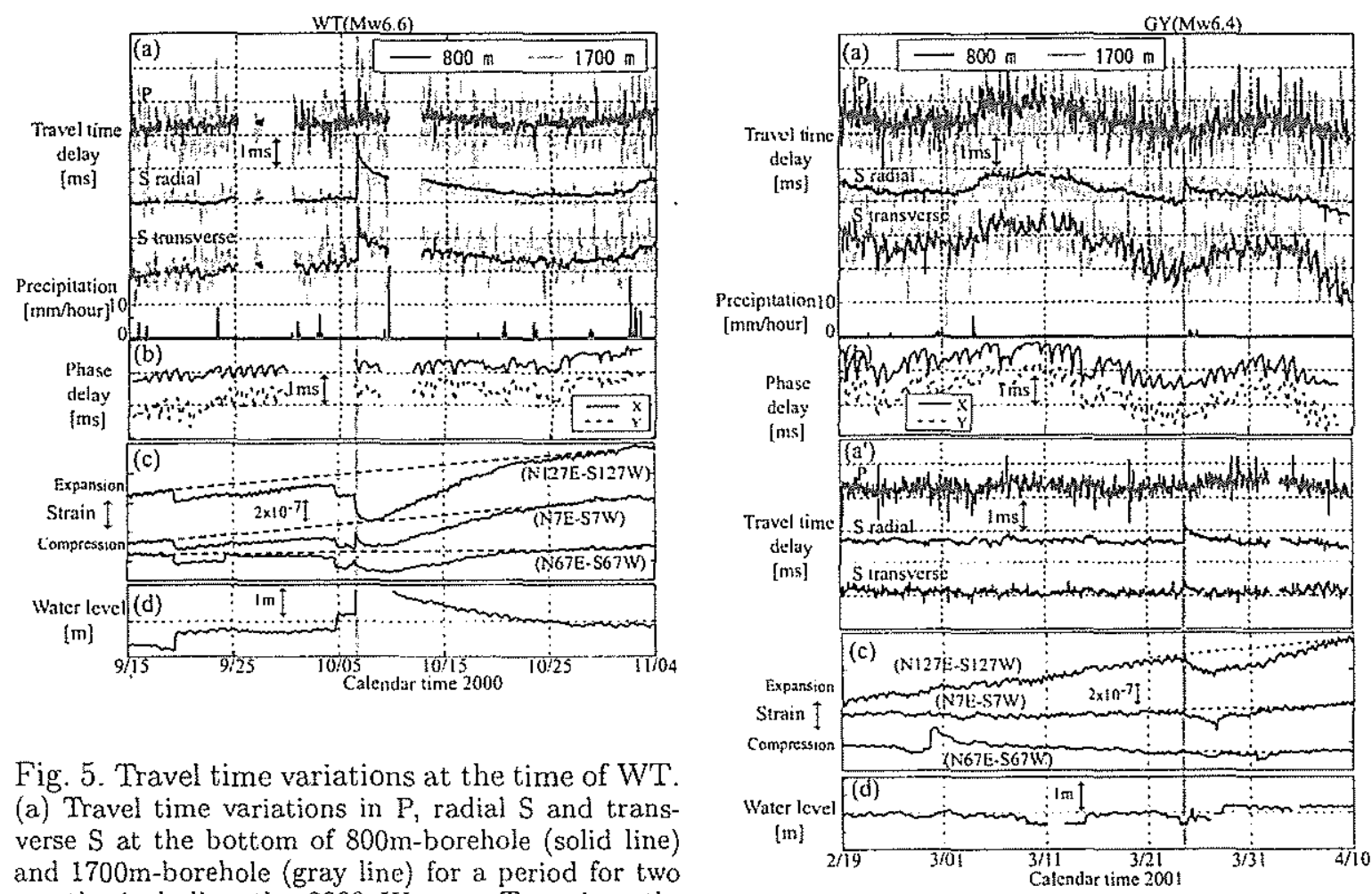

Fig. 5. Travel time variations at the time of WT. (a) Travel time variations in $P$, radial $S$ and transverse $\mathrm{S}$ at the bottom of $800 \mathrm{~m}$-borehole (solid line) and $1700 \mathrm{~m}$-borehole (gray line) for a period for two months including the 2000 Western Tottori earthquake. The vertical gray lines mark the time of the Western Tottori earthquake. Rise means delay of travel time. The bottom shows precipitation. (b) Temporal variation of phase delay near the source, shown by time delay averaged over frequencies. The delay in two horizontal directions are estimated assuming a rigid body motion of the source. (c) Horizontal strain changes at the bottom of the $800 \mathrm{~m}$ borehole. From top to bottom, the strain in $\mathrm{N} 127^{\circ} \mathrm{E}-\mathrm{S} 127^{\circ} \mathrm{W}, \mathrm{S} 7^{\circ} \mathrm{W}-\mathrm{N} 7^{\circ} \mathrm{E}, \mathrm{S} 67^{\circ} \mathrm{W}-\mathrm{N} 67^{\circ} \mathrm{E}$ are shown. Rise means extension. (d) Water level at the $800 \mathrm{~m}$-borehole measured by pressure gauge installed at the top of the borehole. Rise means increase of the pressure.

Fig. 6. Travel time variations at the time of GY.

(a) Same as Fig.5-a. Vertical gray line mark the time of the Geiyo earthquake. (b) Same as ig. 5b with the period including Geiyo earthquake. (a') Corrected travel time variation of the signal at the $800 \mathrm{~m}$-borehole sensor by referring to the vibration near the sources. (c) Same as Fig.5-c). (d) Same as Fig.5-d.

\subsection{Change in the polarized anisotropy of travel time in $\mathrm{S}$ wave}

The sudden delays and the recoveries of the S wave travel times showed clear polarization. The changes in the travel time for the $S$ waves were estimated in six directions with interval 
of 30 degrees perpendicular to the ray path using the three component data of $800 \mathrm{~m}$-borehole sensor. Each variation in the travel time for six directions of $\mathrm{S}$ wave was respectively fitted with exponential decay functions $A \exp (\tau-t) / T$, in which $A$ is the amplitude of the travel time delay in each direction, $t$ is the time of the earthquakes and $T$ is a time constant assumed to be the same for all the directions. As a result, the time constant of recovery $T$ was 2.5 days for the WT earthquake and 1.5 days for the GY earthquake. Figure 7 shows the amplitudes of delays $A$ as a function of polarization angle, in which the maximum delay was commonly observed in $\mathrm{N} 105^{\circ} \mathrm{E}$ direction for both the earthquakes, which is almost perpendicular to the fault strike of the Nojima fault and its sub-fault. It suggests that the increased or inflated cracks were preferentially orientated in a direction parallel to the Nojima fault and its sub-fault.

\subsection{Static anisotropy}

In the previous sections, the temporal variation in the travel time has been estimated by calculating cross-spectral density between the reference and target wave traces, showing the existence of the temporal variations in anisotropy. We made another experiment to check if the static anisotropy exists.

To measure the static anisotropy, we used $\mathrm{S}$ wave splitting. Splitting of $\mathrm{S}$ waves is observed only when the incident $S$ wave polarizes into a certain direction. We generated such a $S$ wave using ACROSS sources. We operated each ACROSS source in normal and reverse rotations alternately and sum the records. Force in direction parallel to the symmetric axis are doubled and that perpendicular to it are cancelled by summation. Then we can consider the summed data to be a signal gen-

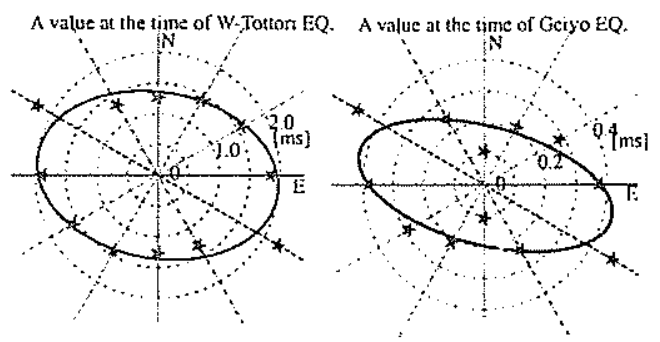

Fig. 7. Polarity in delay time of $S$ waves. (a) Estimated $A$ value in the holizontal six directions at the time of the WT earthquake. Distance of stars from the origin represents the delay of the $S$ wave, which are fitted with an ellipse. Long axis of the ellipse were orientated in the direction $N 100^{\circ} \mathrm{E}$. (b) $A$ value in the holizontal six directions at the time of the GY earthquake. Long axis of the ellipse were orientated in the direction $N 100^{\circ} \mathrm{E}$.

erated by sources linearly vibrating along the axis. Furthermore, the orientation of the axis can be rotated by phase shifting of the records before summing them. We can synthesize virtual signal from the sources, which move linearly in any horizontal directions.

Figure 8-a shows the transferfunction, with the virtual linear-motion sources vibrating in the direction of $\mathrm{N} 50^{\circ} \mathrm{E}-\mathrm{N} 230^{\circ} \mathrm{E}$, recorded with $800 \mathrm{~m}$-borehole sensor. To analyze $\mathrm{S}$ wave splitting, we apply a cross correlation method [e.g., Shin and Meyer, 1990] to it. We calculated cross-correlation coefficient between two extracted $S$ phases for directions from 0 to 180 degrees with increments of 5 degrees and for lag times from 0 to $60 \mathrm{~ms}$ with increments of $2 \mathrm{~ms}$. Direction and lag time which shows maximum correlation coefficient is leading shear-wave polarization direction (LSPD) and delay time (DT), respectively. 


\section{Polarization direction and travel time difference of splitting $\mathrm{S}$ waves}

Figure 8-d shows the cross-correlation computation for the waveform in Figure 8-a. The maximum cross-correlation coefficient $r$ of 0.99 was seen at the rotated angle of $\mathrm{N} 10^{\circ} \mathrm{E}$ and lag time of $50 \mathrm{~ms}$, which are LSPD and DT, respectively. The LSPD coincides with the fault strike, in which the travel time for the $S$ wave showed the minimum temporal change for both WT and GY earthquakes.

The polarization direction of leading $S$ wave LSPD and the travel time difference between two quasi$S$ waves DT calculated with splitting $S$ wave showed the cracks in the direction were originally prevailed. We, therefore, concluded that the increased or inflated cracks were preferentially orientated to the direction parallel to the Nojima fault and its subfault. Existing cracks, which were preferentially orientated in the direction parallel to the faults, could have been suddenly opened by the increase of pore pressure and gradually closed by pressure decrease due to the fluid diffusion. This shows that the shear cracks due to faulting are prevailed even in the portion in $300 \mathrm{~m}$ distance from the fault.

The DT, which indicates the amount of the anisotropy, was 50 ms. This was about $10 \%$ of the absolute travel time between ACROSS sources and $800-\mathrm{m}$ borehole sensor, that seems to be fairly large for the value in the crust.
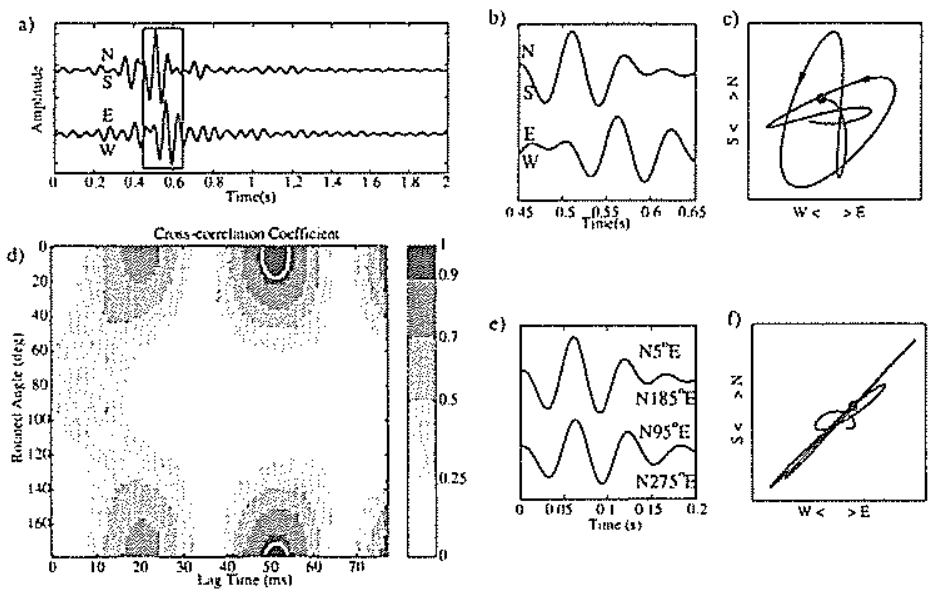

Fig. 8. Splitting analysis.

(a) Transfer functions in horizontal component with ACROSS signal recorded at $800 \mathrm{~m}$-borehole sensor. Rectangular shows the part of $S$ waves. S wave in NS-component seem to arrive faster than that in EW component. (b) Enlarged $S$ wave for the hatched portion in figure 8-a. (c) Particle motion for the wave trace indicated in Figure 8-b. The particle motion initial polarization is $\sim 5^{\circ}$, the computed LSPD, and changes abruptly at the arribal time of the lagging S wave. (d) Result of cross-correlation computation for the waveforms shown in figure 8-b. Absolute values of the cross-correlation coefficient are shown in contour plot. Crosscorrelation value is maximum at the lag time of $52 \mathrm{~ms}$ and at the rotate angle of 5 degrees. (e) Horizontal component seismograms that have been rotated to the leading/lagging coordinate system defined by the computed LSPD $\left(\mathrm{N} 5^{\circ} \mathrm{E}\right)$ and shifted by the computed DT ( $52 \mathrm{~ms}$ ). Two quasi $\mathrm{S}$ phases in the seismograms have similar shapes. (f) Particle motion of Figure 8-e. This "corrected" particle motion is more linear than the original in Figure 8-c. This represents the particle motion of the $S$ wave before splitting.

Tadokoro et al. [1999] studied static anisotropy around this area by using the $\mathrm{S}$ wave splitting with natural earthquakes with focal depths of about $10 \mathrm{~km}$. According to them, DTs were distributed in a range from 30 to $100 \mathrm{~ms}$, which corresponds to a range from 1 to $4 \%$ of the absolute travel times. Although the ratio in our experiment was larger than theirs, the absolute value of DT in our experiment was comparable to their value. This fact 
suggests that most anisotropy around the site should be distributed in the shallower portion.

\subsection{Strain and water pressure}

Temporal changes in the travel time and splitting of $S$ wave showed that a pore pressure inflation in the preferrentially oriented cracks should have changed anisotropy at the times of WT and GY. Let us show that these interpretations explain the other observations, the change in strain and pore pressure measured at the bottom of the borehole.

\section{Areal strain}

Horizontal strain was monitored at the bottom of $800 \mathrm{~m}$ borehole with a three-component strain meter (Figure 5,6). The strain showed anomalous change when both the earthquakes occurred. Ignoring the instantaneous step and subtracting the constant trend, compression after the earthquake and the following recovery were observed. Amount of the compressive strains were up to $4 \times 10^{-7}$ and $3 \times 10^{-8}$ in the case of WT and GY, respectively.

(a)

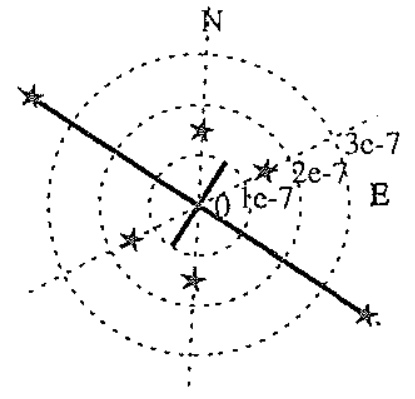

(b)

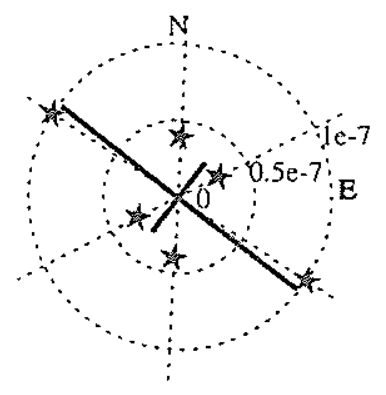

Fig. 9. Horizontal compressive strains.

Strain observed at the time of (a) the WT earthquake and (b) the GY earthquake. Distance of stars from the origin represents the observed compressive strains. Two orthogonal solid line shows the principle strain axes.

$5 \times 10^{-9}$. The observed strains were, therefore, inconsistent with the elastic response to the $5 \times 10^{-9}$ The observed strains were, therefore, inconsistent with the elastic response to the fault dislocations at the sources. The peaks of the observed compressions for both the cases delayed about 2 days from the occurrence of WT and GY, though the peaks of the delay in travel time for the $S$ wave were immediately after the earthquake. This fact can be explained with the pore pressure diffusion, which was described also by the decay pattern of the travel time delay. Pore pressure, which has increased in the shallower portion at the time of each earthquake, should have diffused downward in a following few days. 


\section{Maximum compressive strain axis}

Anisotropy for the strain
changes in the two cases were
similar with each other. Figure 9-a and 9-b shows principal strain axes with the peak values following WT and GY, respectively. The directions of maximum principal strain were orientated to $\mathrm{N} 110^{\circ} \mathrm{E}$, perpendicular to the fault strike for both cases. It can be explained with the preferred orientation of the cracks, which was revealed by the polarized anisotropy of travel time. The polarization anisotropy of travel time shows that most of the existing cracks were aligned parallel to the fault strike, for which the integrated internal pressure over the broad side of the

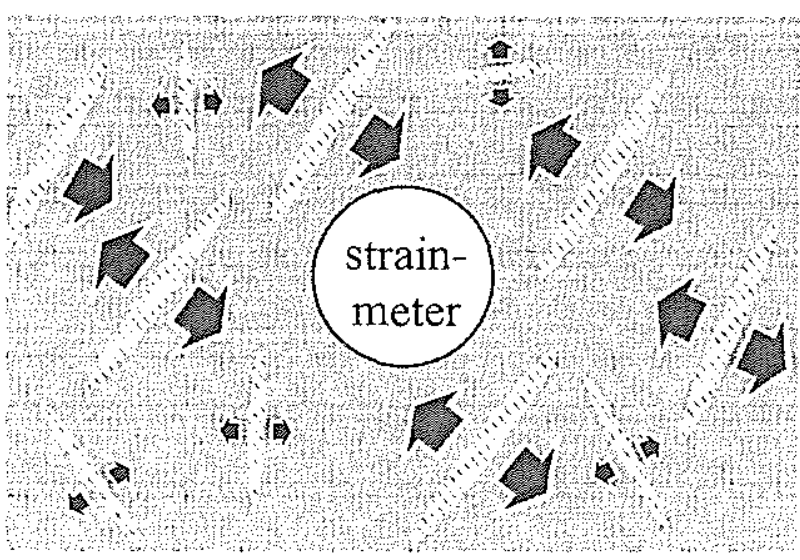

Fig. 10. Schematic illustrations showing the relation between cracks and the strainmeter.

Gray region indicate the matrix granite. Shaded ellipses show fluid saturated cracks. If preferentially orientated cracks (larger ones) are opened by pore pressure inflation, the compressive stress in the normal to the preferred orientation predominate in this medium and the strainmeter is compressed in the direction. cracks could have selectively compressed the strain meter in the direction (See Figure 10) of maximum compressive strain.

\section{Pore pressure}

Water pressure at the bottom of the $800 \mathrm{~m}$-borehole had also been monitored (See Figure 5-d, 6-d). The water in the borehole is supplied through the strainer holes at the bottom; and the pressure is measured at the top, where hole is sealed. We may assume that the change in the pressure we measured is identical to that in the aquifer which connected to the strainers at the bottom. The water pressure increased beyond the range of measurement at the time of $\mathrm{WT}$, which was at least $100 \mathrm{kPa}$, followed by exponential decay in a few days. It is also consistent with the presumption of inflation and diffusion of pore pressure. In contrast to the large increase of water pressure for WT, no increase or decrease was measured at the time of GY. In view of pore pressure inflation, one likely explanation for the lack of response is that permeability around the strainer was significantly reduced after WT. If the strainer was clogged, the water cannot permeate into the borehole. In that case, pore pressure in the surrounding crack can affect on the strain meter without change in water pressure in the well. 


\section{Conclusion}

The temporal variation of seismic velocity near the Nojima Fault, which ruptured during the 1995 Kobe earthquake (Mw 7.2), was monitored using an accurately controlled routineoperated signal system (ACROSS). Sudden decreases of the velocity in $S$ waves were observed when the 2000 Western Tottori earthquake (Mw6.6) and the 2001 Geiyo earthquake (Mw6.4) occurred. The epicenters of them were $165 \mathrm{~km}$ and $215 \mathrm{~km}$ away from the experiment site, respectively. The travel time of the $\mathrm{S}$ wave showed an abrupt delay and a gradual subsequent recovery between surface and bottom of $800 \mathrm{~m}$ deep borehole associated to each earthquake, though little changes were observed in the $\mathrm{P}$ waves. The delay in the $\mathrm{S}$ was about $0.4 \%$ and $0.1 \%$ for the Western Tottori earthquake and Geiyo earthquake, respectively. According to the analysis for anisotropy, the delays were polarized in the direction perpendicular to the Nojima fault. Analysis for static anisotropy using ACROSS also shows that strong anisotropy exists, in which LSPD oriented parallel to the Nojima fault. It can be explained by inflation of water-filled cracks, which were originally prevailed in the direction probably due to the fault dislocation. The preferentially orientated cracks should be opened by sudden increase of pore pressure in shallow portion. The most likely explanation is that pore pressure of ground water in the shallow portion increased by opening of water channels due to the shaking from earthquakes in middle distance. This result explains the anomalous changes appeared in other observations like strain, pore pressure.

\section{Acknowledgements}

A number of people have generously cooperated in this study. In particular, T. Kunitomo; R. Miyajima, T. Okuda, A. Saiga, H. Misu and K. Tsuruga in the field. We thank K. Fujimori, A. Mukai and H. Ito for the permission to use the unpublished data. We specially thank Dr. M. Kumazawa, Dr. K. Tadokoro and Prof. N. Fujii for their critical comments.

\section{References}

Ikuta, R., K. Yamaoka, K. Miyakawa, T. Kunitomo, M. Kumazawa, Continuous monitoring of propagation velocity of seismic wave using ACROSS. Geophys. Res. Lett., 29, 13, 10.1029/2001GL013974, 2002

Naito, H. and S. Yoshikawa, Transrated title; A Program to Assist Crustal Deformation Analysis, Jishin, 2(52), 101-103, 1999

O'Connell, R. J., B. Budiansky, Seismic Velocities in Dry and Saturated Cracked Solids. J. Geophys. Res., 79, 35, 5412-5426. 1974

Shin, X. R., R. P. Meyer, Observation of shear wave splitting from natural events; south moat of Long Valley Caldera, California, June 29 to August 12, 1982. J. Geophys. Res., 95, 7, Pages 11,179-11,195. 1990

Tadokoro, K., M. Ando, and Y. Umeda, S wave splitting in the aftershock region of the 1995 Hyogo-ken Nanbu earthquake J. Geophys. Res., 104,1, Pages 981-991. 1999

Yamaoka, K.,T. Kunitomo, K. Miyakawa, K. Kobayashi, and M. Kumazawa, A trial for monitoring temporal variation of seismic velocity with ACROSS system, The Island Arc, 10, 336-347, 2001 